\title{
DINÂMICA DAS EXPORTAÇÕES DA AMÉRICA LATINA: ECONOMIAS DE ESCALA OU DUMPING RECÍPROCO?*
}

\author{
Jaime Jordán ${ }^{\S}$ \\ José Luiz Parrée
}

\begin{abstract}
RESUMO
O propósito central deste trabalho é verificar se as exportações da América Latina podem ser explicadas pela presença de concorrência monopolista com economias de escala ou oligopólios com dumping recíproco. Para cumprir esse objetivo utilizou-se a técnica de estimar, econometricamente, equações gravitacionais das exportações da América Latina para produtos diferenciados e homogêneos. As informações utilizadas contêm uma extensa relação de registros de operações de exportação de 26 países latino-americanos para 136 países do mundo. Os resultados das estimações econométricas permitem obter as seguintes conclusões: (a) as exportações de bens diferenciados dos países da América Latina são explicadas por um modelo de concorrência monopolista, com rendimentos crescentes e com livre entrada; (b) no caso das exportações de bens homogêneos, elas obedecem a um comportamento de oligopólio com dumping recíproco; (c) a América Latina ainda depende das exportações de bens homogêneos que estão associados à atividade primária.
\end{abstract}

Palavras-chave: exportações, equação gravitacional, comércio internacional e dumping recíproco.

\begin{abstract}
The main concern of this paper is investigated if the Latin American exports is explain for monopolist competition with increasing returns or oligopoly competition with reciprocal dumping. For these propose we used gravitational equation for Latin-American exports for differentiated and homogeneous products. For our econometric estimation we used an extensive sample of exports of 26 Latin-American country's to 136 country's importers of the rest of the world. Our results of the research are the following (a) The Latin-American exports for differentiated goods is explain by monopoly competition and increasing returns with free entry market (b) for homogeneous goods the behavior of regional exports is associated a oligopoly competition with reciprocal dumping (c) The homogeneous goods, with are associated with primary raw materials are yet very important for the economic growth of the Latin-American country's
\end{abstract}

Key words: exports, gravity equation, international trade and reciprocal dumping.

JEL classification: F12, F14, F10.

* Agradecemos os dois pareceristas anônimos da Revista pelas sugestões que possibilitaram o aprimoramento da versão final do artigo.

$\S$ Professor da UNAES - Centro Universitário de Campo Grande. Endereço para contato: UNAES - Centro Universitário de Campo Grande - Av. Fernando Corrêa Costa - Campo Grande - MS 1800 - CEP 79004-311. Fone (67) 3316000. E-mail: jjordancostantini@hotmail.com.

a Professor do Departamento de Economia da Universidade Estadual de Maringá. Endereço para contato: Universidade Estadual de Maringá - Programa de Mestrado em Economia - Av. Colombo, 5790 - Maringá - PR - CEP 87020-900. Fone (44) 32614987 ou 3261-4912. E-mail: jlparre@uem.br.

Recebido em fevereiro de 2006. Aprovado em julho de 2006. 


\section{INTRODUÇÃO}

O propósito central deste trabalho é verificar se as exportações da América Latina podem ser justificadas pela presença de concorrência monopolista com economias de escala ou pela presença de oligopólios com dumping recíproco. Para tanto, apresenta uma metodologia de aplicação empírica fundamentada em equações gravitacionais, com o intuito de provar a validade de teorias alternativas de comércio internacional nas exportações da América Latina, entre os anos 1970-1990.

A crise da década dos oitenta na América Latina teve o efeito de implementar uma nova estratégia comercial na região. Elas incluem políticas unilaterais de abertura econômica para o resto do mundo e desregulamentação do comércio exterior. Estas medidas reduziram as tarifas alfandegárias de $40 \%$ nos anos oitenta para cerca de 12\% nos anos noventa. (Lora 1997). Além disso, os Acordos Preferenciais de Comércio (APC) entre países da região reforçaram essa abertura. Conjuntamente com essa abertura, a América Latina expande seu comércio a taxas superiores à média mundial $(10,8 \%$ contra $6,6 \%)$. Uma das características desse desenvolvimento foi que entre 1970 e 1990 as exportações latino-americanas de manufaturas aumentaram de 11,5\% para 33,1\% do total das exportações. A taxa média de crescimento das exportações manufatureiras da região foi de 10,8\% entre 1970 a 1980 e 6,7\% em 1980-1990. (Fitzgerald, 1997). Considerando-se essas tendências, é importante avaliar se há mudanças nas características da inserção internacional da América Latina entre 1985-1990 relativamente aos anos anteriores.

O artigo está organizado do seguinte modo: a seção dois apresenta uma discussão teórica e metodológica dos aportes das Novas Teorias de Comércio Internacional (New Trade Theories, NTT) para explicar o comportamento dos fluxos de comércio, com destaque para o modelo gravitacional; na seção três expõem-se os fundamentos teóricos e metodológicos que serão aplicados neste trabalho; a seção quatro é reservada à apresentação dos resultados obtidos, e na seção cinco apresentam-se as considerações finais.

\section{A EQUaÇão GRAVITACIONAL}

Há duas correntes teóricas da economia internacional que explicam os fluxos de comércio: Modelos Tradicionais (MT) e Novas Teorias de Comércio Internacional (NTT). O primeiro modelo defende o ponto de vista de que os países se especializam em produzir bens que têm o menor custo de oportunidade, medido em relação a unidades de outro bem. Cabe ressaltar que a teoria dos MT foi associada ao nome de David Ricardo e se baseia em concorrência perfeita dos participantes no comércio internacional. Já a segunda corrente, a NTT, foi desenvolvida por Krugman (1980) e Helpman (1984), entre outros autores. As NTT refletem as realidades do cenário internacional, caracterizadas pelo comércio internacional após a Segunda Guerra Mundial. Isto quer dizer, fundamentalmente, concorrência imperfeita e fluxos de comércio intra-industriais. De acordo com esta corrente teórica, entre outros fatores, o que determina a pauta de exportação são as dimensões do mercado interno, ou seja, as nações não exportam apenas bens nos quais têm vantagens comparativas, mas também aqueles que o mercado doméstico permite produzir em maior quantidade pela presença de rendimentos crescentes de escala em condições de concorrência imperfeita.

De acordo com Davis e Weinstein (1996), a escolha metodológica em um estudo, para provar uma teoria em economia internacional, deve considerar três elementos: primeiro, deve-se escolher um modelo em que, predominantemente, seja tratado o tema das economias de escala; segundo, é necessário ter-se uma proposta teórica que se aplique à realidade; e terceiro, é preciso que se defi- 
nam os contrastes entre as previsões da NTT e da MT. Para Davis e Weinstein (1996), este seria o modelo de efeito do mercado interno (essa proposta metodológica é de autoria de Paul Krugman, 1980). De acordo com tal teoria, os países exportam os bens que mais produzem por ter um mercado interno maior. Essa teoria explica por que grande parte do comércio internacional é gerada entre países industrializados com similar acervo de recursos, o que resulta em contradição se for comparado à versão ingênua das MT, expressa no modelo Hecksher-Olhin.

A metodologia para provar a validade da teoria do "home market effect" baseia-se na equação gravitacional, que é uma regularidade empírica de muito sucesso, que explica os fluxos de comércio entre países e regiões, em função dos níveis de atividade dos países que comercializam internacionalmente. A equação gravitacional foi uma contribuição pioneira de Tinbergen (1962), e uma primeira aplicação foi feita por Poyhonen (1973).

Uma equação gravitacional pode ser expressa da seguinte forma:

$$
\text { Comércio }_{\mathrm{ij}}=\mathrm{Ad} \mathrm{d}_{\mathrm{ij}}^{\beta 1} \mathrm{y}_{\mathrm{it}}^{\beta 2} \mathrm{y}_{\mathrm{jt}}^{\beta 3}
$$

Na equação (1) o comércio entre os países i e j pode ser representado, na forma mais comum, pela soma de exportações ou importações. O comércio é uma função da distância entre os países i e j medida pelo $\mathrm{d}_{\mathrm{ij}}$, e o produto dos países i e j no ano té representado pelas expressões $\mathrm{y}_{\mathrm{it}}$ e $\mathrm{y}_{\mathrm{jt}}$. A, $\beta_{1}, \beta_{2}, \beta_{3}$ são os coeficientes, sendo $\beta_{1}<0, \beta_{2}>0$ e $\beta_{3}>0$. Além disso, $\beta_{2}$ e $\beta_{3}$ são as elasticidadesrenda do país exportador e do país parceiro comercial, respectivamente. Com o objetivo de interpretar os resultados, é mais conveniente usar uma expressão logarítmica como a exposta a seguir:

$$
\operatorname{Ln}\left(\text { Comércio }_{\mathrm{ij}}\right)=\beta_{0}+\beta_{1} \ln \left(\mathrm{d}_{\mathrm{ij}}\right)+\beta_{2} \ln \left(\mathrm{y}_{\mathrm{it}}\right)+\beta_{3} \ln \left(\mathrm{y}_{\mathrm{j} t}\right)+\mathrm{u}_{\mathrm{ij}}
$$

A utilização da equação gravitacional para pesquisar determinados problemas que afetam o comércio requer um vetor de outras variáveis, como, por exemplo, se os países compartilham fronteiras comuns, se são parte de um mesmo acordo regional de comércio, se possuem uma mesma origem colonial etc. Desta forma, a expressão proposta é a seguinte:

$$
\operatorname{Ln}\left(\text { Comércio }_{\mathrm{ij}}\right)=\beta_{0}+\beta_{1} \ln \left(\mathrm{d}_{\mathrm{ij}}\right)+\beta_{2} \ln \left(\mathrm{y}_{\mathrm{it}}\right)+\beta_{3} \ln \left(\mathrm{y}_{\mathrm{j} \mathrm{t}}\right)+\beta^{\prime} \mathrm{X}_{\mathrm{j}}+\mathrm{u}_{\mathrm{ij}}
$$

Nesse caso, $\mathrm{X}_{\mathrm{j}}$ é um vetor-coluna das variáveis adicionais que estão sendo consideradas, $\beta$ ' representa um vetor-linha de coeficientes e $\mathrm{u}_{\mathrm{ij}}$ é o termo randômico. Este vetor $\mathrm{X}_{\mathrm{i}}$ pode representar algumas variáveis como idioma comum, compartilhamento de fronteiras, bem como participação em acordos preferenciais de comércio.

McCallum (1995) pesquisou o comércio entre 30 estados dos EUA e 10 províncias do Canadá utilizando uma equação gravitacional. A descoberta de McCallum foi que os comércios entre as províncias canadenses eram 22 vezes mais importantes do que entre as províncias e os estados dos EUA. O resultado é paradoxal se considerada a livre fronteira entre esses dois países, bem como o fato de que partilham a mesma língua. Esta é, portanto, uma evidência de que o comércio doméstico é muito mais importante que o comércio internacional.

Para Obstfeld e Rogoff (2000), a descoberta de McCallum (1995) é um dos seis enigmas da economia internacional. Se tiver grande segmentação de preços (o agente econômico prefere comercializar mais internamente que externamente), por que a arbitragem internacional não equaciona os preços? Ou seja, se o comércio interno é mais forte que o internacional, os preços internos para um mesmo produto devem ser diferentes do internacional. Prasley e Wei (2000) estudaram a validade da Lei do Preço Único (LPU) em nível internacional, comparando preços de 27 bens comerciáveis internacionalmente de 96 cidades do Japão e dos Estados Unidos por 88 trimestres. A desco- 
berta de Prasley e Wei (2000) foi de que os preços entre Japão e EUA são altamente segmentados. A diferença de preços entre ambos os países, se forem atribuíveis a custos de transporte, é equivalente a dizer que a distância entre os EUA e Japão é de 43 bilhões de milhas. Portanto, os bens nacionais não são perfeitamente competitivos com produtos estrangeiros.

Anderson e Winccop (2001) estudaram novamente a relação comercial entre Canadá e EUA e confirmaram o alto custo de fronteira, mas seu estudo apresenta cifras menores que a estimação feita por McCallum (1995). Anderson e Winccop (2001) apontam que o custo da fronteira depende do tamanho do país, ou seja, em uma economia pequena como a canadense o custo da fronteira é mais alto que nos EUA.

Obstfeld e Rogoff (2000) explicam esse enigma da segmentação internacional de preços pela presença de altas elasticidades Armington. Uma elasticidade Armington mede a substituição entre bens iguais, porém produzidos em países diferentes. Estudos empíricos descobriram que as elasticidades Armington são muito altas e essas elasticidades criam uma segmentação de preços internacionais. Tal segmentação internacional de preços é também conhecida na literatura de economia internacional por custo fronteira, ou viés que um país tem pela sua produção nacional ou, em inglês, home bias. A explicação é de que o alto custo de fronteira descoberto por McCallum pode estar capturando altas elasticidades Armington. Na presença de um fenômeno Armington, um exportador que deseja substituir um consumo doméstico em outro país deverá assumir uma menor receita em suas operações de exportação em relação às suas vendas no mercado interno.

A descoberta de McCallum (1995) determinou o desenvolvimento de uma pesquisa muito ativa em economia internacional com aplicação de equações gravitacionais. Sem pretender fazer uma revisão completa, a equação gravitacional foi extensamente utilizada para desenvolver estudos empíricos em economia internacional (Anderson e Winccop, 2001; Wei, 1996; Nitsh e Sturm, 2004; Davis e Weinstein, 1996), que tinham por objetivo avaliar diversas mudanças institucionais no comércio internacional.

Entre as mudanças internacionais mais pesquisadas estava a crescente expansão dos acordos preferenciais de comércio (APC), a partir de 1980. Este fenômeno é contrastante do multilateralismo vigente depois da Segunda Guerra até 1970. Nos registros da OMC, estabeleceram-se 100 novos APC no mundo, na década de 1990, contra 124 notificações no período 1948-1994. Existe uma grande heterogeneidade de APC e os resultados atingidos por estes são um tema ainda em discussão. A equação gravitacional é o método mais utilizado para pesquisar os efeitos ex-post dos APC. Os modelos de equilíbrio geral têm sido extremamente úteis para examinar os efeitos ex-ante.

Uma aplicação da equação gravitacional, nesse sentido, foi feita por Wei (1996), que ampliou a amostra de McCallum para países da OECD, incluindo outros dois blocos, a antiga EFTA ${ }^{1}$ e a Comunidade Européia - CEE. ${ }^{2}$ O objetivo da pesquisa de Wei (1996) foi investigar o efeito da EFTA e CEE nos custos de fronteira entre 1982 a 1994. Para o estudo de Wei (1996) consideramse o comércio internacional e o comércio interno, ou seja, os bens que um país "exporta" para seu próprio país. Embora o estudo de Wei (1996) tenha como principal problema a medida da distância interna, o resultado foi que os processos de integração estudados reduziram o efeito de fronteira de cada país participante do APC de 9,68 para 2,66. Ou seja, a criação da EFTA e CEE gerou uma redução do custo de fronteira em cada país, mas com um comportamento muito variável.

No Brasil, também foram realizadas pesquisas em economia internacional com a utilização de equações gravitacionais. Os estudos brasileiros com uso de equações gravitacionais podem ser

1 APC formado por: Áustria, Finlândia, Noruega, Suécia e Suíça.

2 APC formado por: Bélgica, Luxemburgo, Dinamarca, França, Alemanha, Grécia, Irlanda, Itália, Portugal, Holanda, Espanha e Reino Unido. 
classificados em dois tipos. O primeiro grupo inclui os trabalhos que trataram de pesquisar os fluxos do comércio entre os países e o efeito dos APC. O segundo inclui os que pesquisaram o efeito dos fluxos do comércio no desenvolvimento regional do Brasil. No primeiro grupo encontram-se os estudos de Piani e Kume (2000) e de Azevedo (2001 e 2004). No segundo grupo, destacam-se os estudos de Porto e Canuto (2002), Porto (2002) e Porto e Canuto (2004) bem como Hidalgo e Vergolino (1998).

O estudo de Piani e Kume (2000) aplica o modelo gravitacional para avaliar os fluxos comerciais entre os diferentes blocos comerciais em nível mundial. Piani e Kume (2000) estabelecem que no caso do Mercosul o efeito no intercâmbio comercial entre os países participantes no bloco foi muito importante de $1992 \mathrm{em}$ adiante, quando comparado com os anos anteriores. As pesquisas de Azevedo (2001 e 2004) têm por objetivo avaliar o efeito do Mercosul no comércio dos países membros, e sua conclusão é que o efeito do Mercosul no comércio intrabloco foi subestimado. A pesquisa de Porto (2002) em alguns aspectos é coincidente com a de Piani e Kume (2000). Em outro estudo, Porto e Canuto (2004) demonstram que os estados brasileiros comercializam muito mais com os países membros do Mercosul do que com países extrabloco.

Cabe observar que Porto e Canuto (2004) oferecem uma interessante contribuição, porque incluem um painel de dados de comércio internacional com dados brasileiros e apresentam uma discussão aprofundada sobre os problemas econométricos envoltos em estimação de uma equação gravitacional com estimativas com efeitos fixos.

\section{Metodologia}

\subsection{Modelo teórico}

A metodologia aplicada neste trabalho foi desenvolvida por Feenstra et al. (2000), que apresentam uma formulação teórica que responde a duas situações: uma de concorrência monopolista para bens diferenciados e outra correspondente a oligopólio com bens homogêneos em mercados segmentados.

\subsubsection{Concorrência monopolista com bens diferenciados}

O modelo desenvolvido por Feenstra et al. (2000) considera dois países que produzem diferentes números de variedades de bens. O consumo em cada país é representado por uma função CES, e cada bem é produzido na mesma quantidade em cada país. Uma condição de equilíbrio é que a demanda do número de variedades de bens de cada país está em proporção direta com o tamanho dos mesmos, ou seja, o país maior terá maior demanda de variedades de bens. Nesta situação, o país maior terá um número maior de empresas entrando para produzir por causa da maior demanda e, portanto, haverá uma maior produção do que no país pequeno, o que faz com que o nível de exportações seja maior que as importações que tal país realiza em relação ao país pequeno. Isto é chamado de efeito do "Home Market" de Paul Krugman. O efeito no mercado interno reflete uma alta recepção de empresas no país maior e, portanto, suas exportações líquidas de bens diferenciados são positivas.

Para aplicar esse resultado teórico em termos de hipóteses testáveis empiricamente tem-se uma expressão simplificada de uma equação gravitacional, que é a seguinte:

$$
\log \mathrm{X}_{\mathrm{ij}}=-\mathrm{A}+\beta_{\mathrm{i}} \log \mathrm{I}_{\mathrm{i}}+\beta \mathrm{j} \log \mathrm{I}_{\mathrm{j}}
$$


Nesse sentido, $X_{\mathrm{ij}}$ são as exportações de bens diferenciados do país i. Analogamente, $\mathrm{X}_{\mathrm{ij}}=\mathrm{n}_{\mathrm{i}} \mathrm{X}_{\mathrm{ii}}$ são as exportações do país j, e Ii, Ij são os níveis de renda dos dois países. Quando Ii for igual a Ij, um aumento em Ii será igual a um decréscimo Ij, ou seja, derivando a equação com relação à renda de cada país tem-se que:

$\mathrm{d}\left(\mathrm{X}_{\mathrm{ij}}-\mathrm{X}_{\mathrm{ij}}\right) / \mathrm{dIi}-\mathrm{d}\left(\mathrm{X}_{\mathrm{ij}}-\mathrm{X}_{\mathrm{ji}}\right) / \mathrm{dIj}>0$, donde se deriva que:

$\mathrm{d}\left(\mathrm{X}_{\mathrm{ij}}-\mathrm{X}_{\mathrm{ij}}\right) / \mathrm{dIi}-\mathrm{d}\left(\mathrm{X}_{\mathrm{ij}}-\mathrm{X}_{\mathrm{ji}}\right) / \mathrm{dI} \mathrm{j}=2(\beta \mathrm{i}-\beta \mathrm{j})>0$ (este valor será positivo apenas quando $\beta \mathrm{i}>\beta \mathrm{j}$ )

Para resumir as hipóteses, tem-se que:

i) Se $\beta_{i}>\beta_{\text {i }}$ em uma equação gravitacional, tem-se um modelo de concorrência monopolista, sendo as exportações mais sensíveis a seu próprio nível de renda do que ao nível de renda do parceiro comercial. Neste caso, existe um efeito do mercado interno sobre a exportação. Trata-se de um caso de um mercado em que a liberdade de entrada gera economias de escala para a exportação.

ii) Se $\beta_{\mathrm{i}}<\beta_{\mathrm{j}}$ em uma equação gravitacional, isto significa que se trata, para o exportador, de um modelo de concorrência perfeita com presença do fenômeno Armington. Neste caso, as exportações são mais sensíveis à renda do parceiro do que à renda do país exportador. No caso em que há a presença do fenômeno Armington, os temas-chave são o consumo e a produção. Assim, a demanda de cada variedade de produtos, sejam eles nacionais ou estrangeiros, será proporcional nos dois países. No entanto, isto não tem relação com a produção. Daí se infere que o país pequeno produz menos que o grande. Portanto, existe um excesso de demanda em relação aos produtos produzidos no país pequeno. O país pequeno é um importador líquido de "x".

\subsubsection{Oligopólio com bens homogêneos em mercados segmentados}

Este conjunto de fenômenos de mercado é conhecido como caso de dumping recíproco e é aplicado à economia internacional, em que a empresa representativa é concorrente Cournot, em uma situação de mercado de livre entrada, no caso de concorrência monopólica, ou de limitações à entrada, no caso de presença de um fenômeno Armington.

Os bens são homogêneos e substitutos perfeitos, e o consumidor tem uma função-utilidade com elasticidade de substituição unitária tipo Coob-Douglas. Um equilíbrio de Cournot é obtido pela igualdade entre a receita marginal e o custo marginal. As firmas determinam seus preços com base em uma margem acima dos custos. O comércio tem uma via dupla, ou seja, as firmas vendem no mercado interno e exportam. O preço de exportação deve ser igual ao preço interno no outro país, menos o custo do transporte. Isso quer dizer que os dois países praticam dumping. Como no país maior há mais empresas, os preços são menores. Portanto, as vendas internas no país de maior dimensão são maiores que as importações e, assim, as receitas do mark-up pelas vendas domésticas são maiores que as receitas do mark-up das importações que as empresas do outro país geram. Em uma situação de equilíbrio de comércio exterior, percebe-se que as empresas do país menor têm prejuízos e as do país maior têm lucros. Por isso, no país maior as exportações excedem suas importações.

Nesta situação, as hipóteses testáveis em uma equação gravitacional são as seguintes:

i) Se $\beta_{\mathrm{i}}>\beta_{\mathrm{j}}$, interpreta-se que com livre entrada e saída dos mercados as exportações são mais sensíveis à renda do país exportador do que à renda do parceiro comercial.

ii) Se $\beta_{\mathrm{i}}<\beta_{\mathrm{i}}$, tem-se uma situação de monopólio no país exportador e, portanto, é mais sensível à renda do parceiro comercial do que à sua renda. 
A visão intuitiva desta proposta é a seguinte: com livre entrada e saída das empresas nos países, as empresas alocadas no país maior exportam para o país menor. Como o preço do bem homogêneo é menor naquele país em relação a este, há uma alocação desproporcional de empresas no país grande que o faz competir de forma monopolista com o outro país.

Os pressupostos teóricos de Feenstra et al. (2000) e as hipóteses de trabalho são as seguintes:

Modelos com livre entrada:

Concorrência não perfeita ou de monopólio $\quad \beta_{\mathrm{i}}>\beta_{\mathrm{j}}$

Dumping recíproco com livre entrada $\quad \quad \beta_{\mathrm{i}}<\beta_{\mathrm{j}}$

Modelos com restrição na entrada:

Diferenciação de produto nacional Armington $\quad \beta_{\mathrm{i}}<\beta_{\mathrm{j}}$

Dumping recíproco sem livre entrada $\quad \quad \quad \beta>\beta \mathrm{j}$

Já as hipóteses de Feenstra et al. (1998) são as seguintes:

$\mathrm{H}_{0}$ ) As barreiras de entrada não estão correlacionadas entre tipos de indústrias (diferenciadas e homogêneas). Ou seja, as elasticidades de exportação e importação não são similares no que diz respeito à magnitude.

$\mathrm{H}_{1}$ ) As indústrias que produzem bens diferenciados têm barreiras à entrada. $\mathrm{O}$ ideal é que os produtos diferenciados possuam barreiras às entradas maiores que os bens homogêneos. Ou seja, $\beta \mathrm{i}<\beta \mathrm{j}$ para bens diferenciados e $\beta \mathrm{i}>\beta \mathrm{j}$ para bens homogêneos.

$\mathrm{H}_{2}$ ) Nessa situação, as barreias à entrada para os bens diferenciados são menores (ou seja, $\beta \mathrm{i}>\beta \mathrm{j}$ ) do que para os bens homogêneos $(\beta \mathrm{i}<\beta \mathrm{j})$. Os bens homogêneos estão relacionados à produção em indústrias básicas como petróleo, ferro etc., que operam em grandes escalas de operação com altos custos fixos e, portanto, com limitações à entrada para novos concorrentes.

Freenstra et al. (1998) testam as hipóteses com estimativas de equações gravitacionais, por produto e por ano, e provam que: (a) as elasticidades de exportação e importação são diferentes e, portanto, rejeitam $\mathrm{H}_{0}$; (b) os bens diferenciados têm menos barreiras à entrada que os bens homogêneos, ou seja, para os bens diferenciados $\beta \mathrm{j}>\beta \mathrm{i}$ e para os bens homogêneos $\beta \mathrm{i}<\beta \mathrm{j}$, portanto, aceitam $\mathrm{H}_{2}$; (c) além disso, apresentam sensibilidade ao modelo e provam que as elasticidades não mudam de forma significativa ao escolher outra subamostra.

As hipóteses supracitadas provam, com a equação gravitacional, o que Freenstra et al. (1998) afirmam, como pode ser observado na expressão a seguir:

$\ln$ Exports $_{\mathrm{ij}}^{\mathrm{k}}=\beta_{0}+\beta_{1} \ln \mathrm{Y}_{\mathrm{i}}+\beta_{2} \ln \mathrm{Y}_{\mathrm{j}}+\beta_{3}$ LnDist $_{\mathrm{ij}}+\beta_{4} \mathrm{ADJ}_{\mathrm{ij}}+\beta_{5}$ Comlang $_{\mathrm{i}}+\beta_{6} \mathrm{c} \_\mathrm{apc}+\beta_{7} \operatorname{LnRem}+\varepsilon_{\mathrm{i}}$

$\mathrm{Na}$ expressão, $\mathrm{k}=1,2,3, \mathrm{k}=1$ se o produto é diferenciado, $\mathrm{k}=2$, se o produto é diferenciado, mas com uma referência de preços, $\mathrm{k}=3$, se o produto é homogêneo. Os significados das variáveis são as seguintes:

$\ln$ Exports $^{\mathrm{k}}{ }_{\mathrm{ij}}-\operatorname{logaritmo}$ das exportações do país i para o país j do produto k;

$\operatorname{lnYi~e~} \operatorname{lnY} \mathrm{j}$ - logaritmos naturais do nível de renda do país i e j;

LnDist $_{\mathrm{ij}}$ - logaritmo natural da distância;

Comlang - variável categórica que assume valor 1 se os dois países falam o mesmo idioma, e 0, em caso contrário; 
LnRem - logaritmo natural da distância relativa, que é a soma das distâncias ponderada pela renda do país, ou seja, $\ln \left(\sum \mathrm{Dist} / \mathrm{Yi}\right)$;

ADJij - variável categórica que assume valor 1 se os dois países têm uma fronteira comum;

c_apc - variável categórica que assume valor 1 se os dois países participam do mesmo APC;

$\varepsilon_{\mathrm{i}}$ - erro aleatório.

Para estimar o modelo, Feenstra et al. (1998) usam uma amostra que contém fluxos de exportações e importações de 136 países durante cinco anos, para cada tipo de produto. Para as estimações os autores utilizam OLS, com variâncias significativas, o que permite obter resultados robustos, que são confirmados por simulações com diferentes amostras.

A aplicação desse modelo requer que se faça a distinção entre os produtos diferenciados e os homogêneos. A contribuição de Rauch (1996) se dá sob a forma de diferenciação entre três tipos de produtos: homogêneos, diferenciados com referência de preço de um mercado organizado, e restante dos produtos (que também são produtos diferenciados). A classificação utilizada tem com base a SITC (Standard International Trade Classification) com três dígitos, que foi construída por Rauch (1996) utilizando a base de dados COMTRADE das Nações Unidas para os anos 1970, 1975, 1980, 1985 e 1990.

Segundo Rauch (1996), os produtos homogêneos são comercializados em mercados organizados. Em geral, os produtos homogêneos têm uma padronização internacional conhecida e aceita por todos os operadores internacionais.

Existem outros produtos que são diferenciados, mas que possuem uma relação com os preços internacionais de mercados homogêneos.

Por último, há milhões de produtos manufaturados heterogêneos que não têm mercados organizados conhecidos, em que a qualidade e a marca têm mais relevância na geração de preços do que as condições de oferta e demanda. Ou seja, os produtos diferenciados têm uma deficiência de informação no concernente a seus preços.

\subsection{Modelo empírico e base de dados}

Serão aplicados os fundamentos teóricos de Feenstra et al. (1998) com o objetivo de testar se as exportações da América Latina satisfazem as hipóteses que foram comprovadas para a amostra mundial, ou seja, que os bens diferenciados têm menores barreiras à entrada que os bens homogêneos. A especificação da equação gravitacional a ser aplicada é idêntica à que foi utilizada por Feenstra et al. (1998), e que está representada pela equação (4).

Utiliza-se uma amostra ampliada da América Latina, tomando como países exportadores todos os países da América do Sul, da América Central, bem como o México e o Caribe, considerando realidades diversas como o tamanho dos países, origem colonial e diferenças culturais e de idiomas, além de examinar atentamente os países que participam em diferentes APC.

Um ponto a que se faz referência em uma das equações gravitacionais são os diferentes APC internacionais. Assim sendo, para esclarecer melhor o tema, no Quadro 1 apresentam-se os países que são considerados em cada APC.

Como é possível observar, alguns APC ocorreram após a década de 1990, como são os casos do Mercosul e do Nafta. Como o presente estudo analisa o período 1970-1990, o Mercosul e o Nafta não deveriam ser incluídos. Porém, pesquisadores, como, por exemplo, Nischt e Sturm (2004), que estudam os efeitos dos APC, consideram que as subscrições dos acordos por parte dos governos só 
facilitam o comércio inter-regional. O comércio entre países é dinâmico e é anterior aos convênios, feitos pelos governos, mediante tratados internacionais. Portanto, os APC do Mercosul e Nafta devem ser considerados. Neste sentido, cabe apresentar como exemplo Azevedo (2001, p. 12), que considera um período de integração, de 1987 a 1990, para ao Mercosul.

Quadro 1 - Diferentes APC que participam os países da América Latina

\begin{tabular}{|l|c|l|}
\hline APC & Data de Início & \multicolumn{1}{|c|}{ Países Membros } \\
\hline Mercado Comum Centro-americano & 1960 & El Salvador, Guatemala, Nicarágua, Costa Rica, Honduras \\
\hline Comunidade Andina (CA) & 1969 & Bolívia, Colômbia, Equador, Peru, Venezuela \\
\hline Comunidade do Caribe (CARICOM) & 1973 & $\begin{array}{l}\text { Antiga e Bermuda, Barbados, Bahamas, Dominica, Haiti, Granada, } \\
\text { Guiana, Jamaica, Trinidad e Tobago, St. Crist. E Nevis, St. Vicent, St. } \\
\text { Lucia }\end{array}$ \\
\hline Mercado Comum do Sul (MERCOSUL) & 1995 & Argentina, Brasil, Paraguai, Uruguai \\
\hline $\begin{array}{l}\text { Associação Latina Americana de } \\
\text { Integração (ALADI) }\end{array}$ & 1965 & $\begin{array}{l}\text { Argentina, Brasil, Bolívia, Equador, Colômbia, Cuba, México, Peru, } \\
\text { Paraguai, Uruguai, Venezuela }\end{array}$ \\
\hline $\begin{array}{l}\text { Tratado de Livre comércio da América } \\
\text { do Norte (NAFTA) }\end{array}$ & 1994 & México, EUA, Canadá \\
\hline
\end{tabular}

Fonte: BID (2002).

A trajetória típica de um APC tem o formato da letra $\mathrm{S}$, ou seja, os países que farão parte de um APC têm um crescimento importante no comércio recíproco antes da subscrição do acordo, que aumenta quando o APC se formaliza, tendendo a se estabilizar, com o passar do tempo, quando as possibilidades de comércio se esgotam. De acordo com as considerações anteriores, para efeito de estimação serão considerados os APC da Associação Latino-americana de Integração (Aladi), Mercado Comum Centro Americano e Comunidade do Caribe (CARICOM) a partir de 1970, o Nafta a partir de 1985, e o Mercosul a partir de 1990.

Como os diferentes APC considerados têm características muitos diferentes umas das outras, o parâmetro associado ao APC deve ser interpretado como um indicador do efeito do comércio interregional da América Latina.

A base de dados para as estimações econométricas é a mesma utilizada por Feenstra $e t a l$. (1998), e está disponível no site http://faculty.haas.berkeley.edu/arose/. Os dados referem-se a exportações e importações de 136 países, para os anos 1970, 1975, 1980, 1985, 1990, ${ }^{3}$ classificados por bens diferenciados, diferenciados com preços de referência e homogêneos. Essa base de dados foi transformada para considerar dois vetores: um de países exportadores composto por 26 países da América Latina e outro composto por 136 países importadores (a lista completa com todos os países da amostra está no Apêndice ao final do artigo). A base de dados foi analisada para verificar se a amostra reflete o comportamento do comércio exterior da América Latina. A Tabela 1 apresenta a avaliação.

O comportamento da amostra utilizada e as características mais destacadas seguem os padrões do que foram as tendências do comércio da América Latina. A trajetória típica das exportações da América Latina foi de redução nos primeiros cinco anos da década de 1980 e de crescimento na segunda parte da década, de acordo com Fitzgerald (1997).

3 Os dados que Feenstra et al. (2000) utilizam, e que são utilizados neste trabalho, são produto da classificação de Rauch (1996) em bens diferenciados e homogêneos, sendo 1990 o último ano disponível. 
Tabela 1 - Estrutura e dinâmica das exportações dos países da América Latina

\begin{tabular}{|c|c|c|c|c|}
\hline Ano & $\begin{array}{c}\text { Diferenciados } \\
\%\end{array}$ & $\begin{array}{c}\text { Diferenciados com } \\
\text { preços de referência } \\
\%\end{array}$ & $\begin{array}{c}\text { Homogêneos } \\
\%\end{array}$ & $\begin{array}{c}\text { Total } \\
\%\end{array}$ \\
\hline 1970 & 31,4 & 38,6 & 30,0 & 100,0 \\
\hline 1975 & 31,2 & 39,9 & 28,9 & 100,0 \\
\hline 1980 & 31,6 & 39,6 & 28,8 & 100,0 \\
\hline 1985 & 32,4 & 39,3 & 28,3 & 100,0 \\
\hline 1990 & 32,9 & 40,2 & 26,9 & 100,0 \\
\hline \multicolumn{5}{|c|}{ Taxas de crescimento ao ano } \\
\hline $1970-90$ & 1,5 & 1,5 & 0,7 & 1,28 \\
\hline $1980-85$ & 0,2 & $-0,5$ & $-0,6$ & $-0,3$ \\
\hline $1985-90$ & 3,5 & 3,7 & 2,1 & 3,3 \\
\hline
\end{tabular}

Fonte: Elaboração própria.

Outro diagnóstico a ser feito refere-se às características da base de dados com propósito de efetuar a estimação econométrica. Para tanto, para cada tipo de produto (diferenciado, diferenciado com preços de referência e homogêneos) e para cada ano estima-se uma equação gravitacional com o método de mínimos quadrados (OLS). Essas equações gravitacionais foram testadas para verificar a presença de outliers, colinearidade (teste de inflação de variâncias), heteroscedasticidade (testes de Breusch-Pagan e Cook-Weinsber), normalidade dos erros (Shapiro-Wilkson,), variáveis omitidas (teste de Ramsey) e teste dos erros de especificação e autocorrelação (Durbin-Watson). Os resultados dos testes demonstraram que a amostra possui outliers influentes, sendo heteroscedástica, não há normalidade na distribuição dos erros e também existem variáveis omitidas e erros de especificação. Os problemas abordados e corrigidos, na medida do possível, foram a presença de outliers, heteroscedasticidade e verificação do viés que gera as variáveis omitidas.

O método para detectar os outliers influentes é o seguinte: calcula-se para cada ano a equação gravitacional com o método de OLS e identificam-se e excluem-se os outliers influentes para cada equação gravitacional. Existe uma equação gravitacional para cada ano e tipo de produto.

Os problemas de heteroscedasticidade não geram parâmetros tendenciosos, mas os testes de hipótese podem levar a conclusões erradas. Para evitar tal imperfeição, utilizou-se o método OLS com variâncias robustas do tipo Huber/White/Sandwich. Foi o mesmo sistema de estimação utilizado por Feenstra et al. (2000). Já Piani e Kume (2000) estimaram com o WLS (sistema de White). Como os resultados dos testes evidenciaram a existência de variáveis omitidas, estimaram-se os parâmetros das equações gravitacionais pelo sistema de efeitos fixos, ${ }^{4}$ por variável categórica, para verificar se o viés dos parâmetros na estimação por OLS apresentava um nível de significância que poderia invalidar as principais conclusões do presente trabalho.

Os resultados aqui obtidos permitem asseverar que as conclusões não mudam fundamentalmente pelo fato de se utilizar o sistema de efeitos fixos ou OLS. A utilização e apresentação do método do OLS possibilitam, adicionalmente, estabelecer um paralelo entre nossas estimações e aquelas da amostra mundial estimada por Feenstra et al. (2000).

4 As estimativas das equações por efeitos fixos não serão apresentadas neste trabalho. 
Um dos problemas ao estimar as equações gravitacionais ocorre quando, em determinadas observações, não existem transações entre dois países. Pelo tipo de função que se especifica, o logaritmo de zero não tem sentido. Para este caso, há duas alternativas: eliminar as observações com transações zero, ou somar tais transações a 1 . O segundo procedimento fundamenta-se em que log $(1+x)$ é muito próximo a log (x). Azevedo (2001) faz sua escolha por ambos os métodos e apresenta os resultados. Em nossas estimações só apresentamos um resultado, ou seja, assumindo que log $(1+\mathrm{x})=\log (\mathrm{x})$.

\section{Resultados}

Com base na discussão apresentada, o procedimento econométrico aplicado foi o seguinte: foram obtidas estimações da equação gravitacional especificada na equação (4) para cada ano e produto. A análise dos resultados da Tabela 2 permite que se façam as observações que expomos na seqüência.

Tabela 2 - Resultados das equações gravitacionais para a América Latina

\begin{tabular}{|c|c|c|c|c|c|c|c|c|c|}
\hline \multicolumn{10}{|c|}{$\operatorname{lnExports}{ }_{\mathrm{ij}}^{\mathrm{k}}=\beta_{0}+\beta_{1} \ln \mathrm{Y}_{\mathrm{i}}+\beta_{2} \ln \mathrm{Y}_{\mathrm{j}}+\beta_{3} \mathrm{LnDist}_{\mathrm{ij}}+\beta_{4} \mathrm{ADJ}_{\mathrm{ij}} \beta_{5}$ Comlang $+\beta_{6} \mathrm{c}-{ }_{\mathrm{apc}}+\beta_{7} \mathrm{REM}+\varepsilon_{\mathrm{i}}$} \\
\hline \multicolumn{10}{|c|}{ A. Produtos diferenciados } \\
\hline Ano & $\beta_{1}$ & $\beta_{2}$ & $\beta_{3}$ & $\beta_{4}$ & $\beta_{5}$ & $\beta_{6}$ & $\beta_{7}$ & $\mathrm{~N}$ & $\mathrm{R}^{2}$ \\
\hline 70 & $0,90^{*}$ & $0,61^{*}$ & $-1,68^{*}$ & $0,66^{* * *}$ & $1,12^{*}$ & $1,49^{*}$ & $496^{*}$ & 965 & 0,54 \\
\hline 75 & $1,03^{*}$ & $0,66^{*}$ & $-1,90^{*}$ & 0,39 & $0,89^{*}$ & $0,89^{*}$ & $979^{*}$ & 1.509 & 0,51 \\
\hline 80 & $1,19^{*}$ & $0,54^{*}$ & $-1,69^{*}$ & 0,39 & $1,09^{*}$ & $1,49^{*}$ & $1.700^{*}$ & 1.397 & 0,51 \\
\hline 85 & $1,00^{*}$ & $0,51^{*}$ & $-1,49^{*}$ & $-0,09$ & $0,99^{*}$ & $0,87^{*}$ & $1.669^{*}$ & 1.486 & 0,43 \\
\hline 90 & $1,02^{*}$ & $0,62^{*}$ & $-1,53^{*}$ & 0,51 & $0,71^{*}$ & $0,97^{*}$ & $2.304^{*}$ & 1.286 & 0,48 \\
\hline \multicolumn{10}{|c|}{ B. Produtos diferenciados com preços de referência } \\
\hline 70 & $0,92^{*}$ & $0,60^{*}$ & $-1,23^{*}$ & 0,12 & 0,23 & $1,88^{*}$ & $696^{*}$ & 1.191 & 0,38 \\
\hline 75 & $0,96^{*}$ & $0,66^{*}$ & $-1,73^{*}$ & 0,50 & $0,56^{*}$ & $0,77^{*}$ & $1.336^{*}$ & 1.277 & 0,39 \\
\hline 80 & $1,05^{\star}$ & $0,64^{*}$ & $-1,46^{*}$ & $0,87^{\star}$ & $0,72^{*}$ & $1,04^{*}$ & $1.140^{*}$ & 1.293 & 0,38 \\
\hline 85 & $1,00^{*}$ & $0,64^{*}$ & $-1,37^{*}$ & 0,16 & $0,98^{*}$ & $0,98^{*}$ & $1.515^{\star}$ & 1.334 & 0,36 \\
\hline 90 & $1,08^{*}$ & $0,77^{*}$ & $-1,49^{*}$ & 0,14 & $0,54^{*}$ & $1,05^{*}$ & $1.484^{*}$ & 1.254 & 0,44 \\
\hline \multicolumn{10}{|c|}{ C. Produtos homogêneos } \\
\hline 70 & $0,81^{*}$ & $0,74^{*}$ & $-1,23^{*}$ & 0,20 & $-0,25$ & $1,44^{*}$ & 522 & 1.133 & 0,35 \\
\hline 75 & $0,89^{*}$ & $0,88^{*}$ & $-1,28^{*}$ & 0,33 & $-0,23$ & $0,76^{*}$ & $853^{* *}$ & 1.185 & 0,31 \\
\hline 80 & $0,98^{*}$ & $1,01^{*}$ & $-1,34^{*}$ & 0,06 & 0,01 & $0,44^{*}$ & 628 & 1.211 & 0,28 \\
\hline 85 & $0,89^{*}$ & $0,83^{*}$ & $-1,20^{*}$ & 0,08 & $-0,38$ & $0,57^{*}$ & 779 & 1.264 & 0,29 \\
\hline 90 & $0,79^{*}$ & $0,99^{*}$ & $-1,39^{*}$ & 0,44 & $-0,29$ & $0,77^{*}$ & 343 & 1.143 & 0,35 \\
\hline
\end{tabular}

Fonte: Resultados da pesquisa.

* significativo a $1 \% ;{ }^{* *}$ significativo a $5 \% ;{ }^{* *}$ significativo a $10 \%$.

As equações gravitacionais obtidas conseguem capturar o comportamento das exportações da América Latina nos anos considerados. Os sinais dos coeficientes estão de acordo com o esperado, quando estes são estatisticamente significativos. Em relação às elasticidades das exportações e ao 
produto, esta é maior para o caso de bens diferenciados do que para os bens homogêneos. Na amostra mundial utilizada por Feenstra et al. (1998), têm-se os mesmos resultados, mas as elasticidades de exportação em relação à renda do país exportador, para o caso de bens homogêneos, são menores do que em nossas estimações.

O ajuste da equação gravitacional é melhor quando se trata de bens diferenciados. Isto ocorre devido ao fato de o nível do coeficiente de determinação ser mais baixo para os bens homogêneos do que para os bens diferenciados (última coluna da Tabela 2). Além disso, os parâmetros associados às variáveis categóricas, como idioma comum ou compartilhamento de uma fronteira $\left(\beta_{4}\right.$ e $\left.\beta_{5}\right)$, não são significativos para os bens homogêneos. Isto significa que o comércio internacional de bens homogêneos da América Latina não se comporta de acordo com um modelo gravitacional. Ou seja, os produtos homogêneos são embarcados para países distantes, onde os fatores do tipo cultural, como a língua comum, não têm um papel importante no comércio. Esta situação é possível por se tratar de comércio em mercados organizados com informação de preços e por se tratar de bens homogêneos.

Para os bens diferenciados exportados pela América Latina, a situação é a seguinte: os parâmetros $\left(\beta_{5}\right)$ são significativos em todos os anos. Interpreta-se $\beta_{5}$ como uma variável proxy de elementos culturais. Pode-se afirmar que para o comércio de bens diferenciados esses tipos de fatores são relevantes. Além disso, o valor de $\beta_{5}$ é mais significativo para bens diferenciados do que para os bens diferenciados com referência a preços, o que demonstra que o parâmetro $\beta_{5}$ é afetado pela escassez de informação de preços em mercados diferenciados, que não possuem um esquema organizado de definição de preços; o contrário acontece com os produtos básicos, onde existem bolsas que geram informações de preços. Assim, por não disporem de informação de preços, os exportadores de bens diferenciados desenvolvem comércio principalmente com aqueles países com os quais têm afinidades culturais.

Outra diferença importante entre bens diferenciados e homogêneos exportados pela América Latina se dá no concernente à elasticidade das exportações com relação à distância $\left(\beta_{3}\right)$. Para os bens homogêneos, esta elasticidade é menor quando comparada à dos bens diferenciados. Tal resultado capta uma situação de arbitragem de preços em ambos os tipos de bens. A margem de arbitragem de preços nos bens diferenciados é maior do que nos bens homogêneos, e isto se deve a uma escassez de informação de preços dos bens diferenciados. Os preços não têm uma relação tão direta com a oferta e a demanda. Nesse tipo de bens, o exportador tem que buscar um cliente e, portanto, deverá existir uma rede de comércio complexa. Essa rede se sustenta com maiores margens de arbitragem de preços.

Outro resultado relevante apresentado na Tabela 2 é a resposta para a seguinte questão: qual é o efeito dos APC nas exportações da América Latina? Os APC criam um mercado mais amplo para as exportações da América Latina do que os mercados internos de cada país. Nos anos considerados no presente estudo não se observa uma tendência clara. Este fenômeno é capturado pela equação gravitacional no parâmetro $\beta_{6}$. Para os anos de 1970 e 1980, nos dois tipos de bens diferenciados, o parâmetro $\beta_{6}$ tem um valor muito alto. A interpretação desse parâmetro é a seguinte: se $\beta_{6}=1,88$ (corresponde aos bens diferenciados no ano de 1970), isto quer dizer que os participantes do acordo comercial comercializam 6,5 vezes $\left(e^{1,88}=6,55\right)$ mais entre eles do que com outros países que não participam do APC; nos outros anos, o parâmetro $\beta_{6}$ varia entre um valor mínimo de 0,77 a um máximo de 1,05 , sem apresentar uma tendência, no tempo, muito clara. Mas os valores do parâmetro sob análise são muito diferentes para os bens diferenciados quando comparados com os bens homogêneos. O parâmetro $\beta_{6}$ para os bens homogêneos apresenta valores menores do que para os bens diferenciados. Esse resultado mostra que os APC favorecem o comércio de bens diferenciados da América Latina. 
Eichengreen e Irwin (1994) explicam que altos níveis dos parâmetros associados aos APC, em períodos de pré-integração, são decorrentes de um relacionamento histórico de longos anos e de cadeias de empresas que atuam em diferentes países, os quais não são capturados pelas equações gravitacionais.

As elasticidades de exportação da América Latina em relação à renda do país exportador são maiores que as elasticidades do produto do parceiro comercial, para os dois tipos de bens diferenciados (painéis A e B da Tabela 2). No caso de bens diferenciados, as elasticidades de exportação em relação ao produto do país exportador $\left(\beta_{1}\right)$ estão no nível de 0,90 na estimação de 1970 , valor este que aumenta para 1,19 em 1980, para então baixar, nos anos seguintes, para um valor próximo à unidade. Para os bens diferenciados com referência de preços, ocorre um aumento que é ainda maior nos anos 1985-1990 relativamente ao período anterior. Os bens diferenciados com referência de preços estão associados a produtos intermediários. Buitelar e Martens (1996) apontaram que os bens mais dinâmicos nas exportações da América Latina foram os bens intermediários. Como $\beta_{1}>\beta_{2}$, isto significa que efetivamente as exportações da América Latina nos bens diferenciados respondem a uma estrutura de concorrência monopolista e de livre entrada e saída, com presença de economias de escala.

Para os bens homogêneos, a situação é a seguinte: em 1970 e 1975 não se pode defender o ponto de vista de dumping recíproco com livre entrada, porque estatisticamente $\beta_{1}=\beta_{2}$; para 19851990 , pode-se afirmar que as exportações de bens homogêneos se configuram como uma organização industrial com concorrência monopolista e dumping recíproco com livre entrada. Os bens homogêneos, tipicamente matérias-primas, têm um papel importante nas exportações, mas essa dependência baixa depois de 1985.

Com objetivo de aprofundar a pesquisa, foram analisadas subamostras com vistas a sensibilizar os resultados e determinar se a amostra gera resultados estáveis para os parâmetros. Para esse efeito, estudou-se uma subamostra intralatino-americana, em que os exportadores e importadores são países da região. Uma segunda subamostra considerou o comércio entre os países da América Latina e os países da OECD. Para facilitar a análise foram estimadas equações gravitacionais agregando os dois tipos de bens diferenciados para os anos 1975, 1980 e 1990. Os resultados são apresentados na Tabela 3.

Confirma-se que para os dois tipos de bens diferenciados, em sua relação comercial entre os países da América Latina, existe competição monopolista e de livre entrada com economias de escala. As elasticidades de exportação em relação à renda do país exportador são maiores que as elasticidades de exportação em relação ao parceiro comercial. As elasticidades de exportação em relação à renda dos países exportadores são um pouco mais altas para a amostra do comércio regional do que para a amostra original. Isso quer dizer que exportações de bens diferenciadas são muito mais sensíveis às exportações regionais do que às extra-regionais. Esse resultado é um reflexo de que o comércio regional adquire mais importância que o comércio extra-regional nos anos oitenta. Esse efeito é muito mais intenso na segunda metade da década de 1980.

Para o comércio de bens diferenciados entre América Latina e os países da OECD, observa-se que $\beta_{1}<\beta_{2}$. Ou seja, os países da OECD têm economias de escala em relação aos países da América Latina. Este resultado é muito consistente com a realidade: os países da América Latina são importadores de bens diferenciados da OECD. 
Tabela 3 - Coeficientes da equação gravitacional para as subamostras.

\begin{tabular}{|c|c|c|c|c|c|c|c|c|c|}
\hline \multicolumn{10}{|c|}{$\operatorname{lnExports}_{\mathrm{ij}}^{\mathrm{k}}=\beta_{0}+\beta_{1} \ln \mathrm{Y}_{\mathrm{i}}+\beta_{2} \ln \mathrm{Y}_{\mathrm{j}}+\beta_{3} \mathrm{LnDist}_{\mathrm{ij}}+\beta_{4} \mathrm{ADJ}_{\mathrm{ij}} \beta_{5}$ Comlang $+\beta_{6} \mathrm{c}-\mathrm{pc}+\beta_{7} \mathrm{REM}+\varepsilon_{\mathrm{i}}$} \\
\hline \multicolumn{10}{|c|}{ Comércio Intralatino-americano } \\
\hline \multicolumn{10}{|c|}{ A. Produtos diferenciados } \\
\hline Ano & $\beta_{1}$ & $\beta_{2}$ & $\beta_{3}$ & $\beta_{4}$ & $\beta_{5}$ & $\beta_{6}$ & $\beta_{7}$ & $\mathrm{nn}$ & $\mathrm{R}^{2}$ \\
\hline 1975 & $0,99^{*}$ & $0,33^{*}$ & $-2,19^{*}$ & $0,38^{* *}$ & $0,28^{*}$ & $1,27^{*}$ & $1.960^{*}$ & 1.188 & 0,48 \\
\hline 1980 & $1,09^{*}$ & $0,21^{*}$ & $-1,84^{*}$ & 0,87 & 0,87 & $1,60^{*}$ & $1.571^{*}$ & 1.156 & 0,54 \\
\hline 1990 & $1,15^{*}$ & $0,29^{*}$ & $-2,19^{*}$ & $-0,17$ & 0,22 & $1,48^{*}$ & $3.249^{*}$ & 1,066 & 0,55 \\
\hline \multicolumn{10}{|c|}{ B. Produtos homogêneos } \\
\hline 1975 & 0,89 & 0,22 & $-1,35$ & $0,87^{* *}$ & 0,18 & $1,59^{*}$ & 1.229 & 324 & 0,33 \\
\hline 1980 & 0,81 & 0,30 & $-1,89$ & 0,22 & 0,12 & $1,66^{*}$ & $2.059^{* *}$ & 326 & 0,29 \\
\hline 1990 & 0,89 & 0,40 & $-2,02$ & 0,24 & 0,27 & $1,31^{*}$ & $2.884^{*}$ & 324 & 0,36 \\
\hline \multicolumn{10}{|c|}{ Comércio Latino-americano OECD } \\
\hline \multicolumn{10}{|c|}{ A. Produtos diferenciados } \\
\hline 1970 & $0,98^{*}$ & $1,66^{*}$ & $-0,78^{*}$ & 0,23 & $0,97^{*}$ & $\mathrm{SI}$ & $2.659^{*}$ & 875 & 0,54 \\
\hline 1980 & $0,99^{*}$ & $1,62^{*}$ & $-0,93^{*}$ & $-0,27$ & 0,77 & $\mathrm{SI}$ & $3.614^{* *}$ & 1.013 & 0,54 \\
\hline 1990 & $0,91^{*}$ & $1,47^{*}$ & $-1,09^{*}$ & $-0,05$ & 1,44 & SI & $2.554^{*}$ & 909 & 0,55 \\
\hline \multicolumn{10}{|c|}{ B. Produtos homogêneos } \\
\hline 1970 & $0,99^{*}$ & $1,29^{*}$ & $-1,15^{*}$ & $-1,44^{* *}$ & 1,05 & $\mathrm{SI}$ & $1.397^{* *}$ & 319 & 0,44 \\
\hline 1980 & $1,13^{*}$ & $1,54^{*}$ & $-1,01^{*}$ & $-0,76$ & 1,64 & $\mathrm{SI}$ & 1.113 & 321 & 0,45 \\
\hline 1990 & $0,87^{*}$ & $1,42^{*}$ & $-0,97^{*}$ & 1,51 & 1,22 & SI & $1.343^{* *}$ & 293 & 0,49 \\
\hline
\end{tabular}

Fonte: Resultados da pesquisa.

* significativo a $1 \% ;{ }^{* *}$ significativo a $5 \% ;{ }^{* *}$ significativo a $10 \%$. SI - Sem Informação.

Do ponto de vista dos produtos homogêneos, segundo a Tabela 3, podem ser observados dois tipos de comportamento dos exportadores latino-americanos, dependendo do mercado a que se refere. No caso dos mercados intralatino-americanos, como expressa Feenstra et al. (2000, p. 14), trata-se de "reverse home market effect", ou seja, de economias de escala na produção de bens homogêneos com concorrência monopolista e com barreiras à entrada. Mas para as exportações para o resto do mundo, observa-se o comportamento de um dumping recíproco com livre entrada, porque $\beta_{1}<\beta_{2}$.

Os resultados capturam um fenômeno muito claro: a América Latina é um mercado pouco relevante para os exportadores de bens homogêneos da região. Ao mesmo tempo, no comércio regional o exportador da América Latina de bens homogêneos tem um poder de mercado com barreiras à entrada por efeito de grandes escalas de produção e altos custos fixos. Este é o caso das empresas exportadoras de matérias-primas da América Latina nos setores do aço, ferro, petróleo, cobre etc. Nas exportações extra-regionais de bens homogêneos, observa-se um comportamento mais claro, o que possibilita identificar um oligopólio com práticas de dumping. Os produtos básicos da região não têm por destino fundamental outros países da América Latina. Os mercados dos produtos básicos da região são os países industriais. O comportamento dominante de um exportador da América Latina é, portanto, de oligopólio com dumping recíproco.

A análise de sensibilidade realizada permite ainda avaliar se as conclusões obtidas são razoavelmente sólidas. Isto é, se as elasticidades de exportação em relação ao produto do país exportador 
$\left(\beta_{1}\right)$ são estáveis, independentemente da amostra e dos anos considerados. As elasticidades para os bens diferenciados são razoavelmente estáveis.

No caso da amostra e em todas as subamostras, a elasticidade das exportações em relação à renda do país exportador está no intervalo de um mínimo de 0,90 a um máximo de 1,15. No caso dos bens homogêneos, as elasticidades de exportação em relação ao produto do país exportador são razoavelmente estáveis. Para os bens homogêneos, em todas as subamostras os valores flutuam em um intervalo de um mínimo de 0,79, para a amostra total no ano 1990 (Tabela 2), e um máximo de 1,13, para a subamostra de comércio com os países da OECD do ano 1980 (Tabela 3). Na década de 1980, os preços das matérias-primas tiveram um comportamento negativo para os exportadores da região. Nessas condições, não havia incentivos para aumentar as exportações de bens homogêneos, fato este que explica porque ocorreu uma diminuição das elasticidades de exportações dos bens homogêneos.

Um dos resultados da amostra mundial de Feenstra et al. (1998) foi que as elasticidades de exportação com relação ao país exportador são diferentes de acordo com o tipo de produto; por exemplo, a elasticidade de exportação de bens diferenciados está próxima de 1; por outro lado, a elasticidade exportação para bens homogêneos é muito menor: entre 0,4 e 0,5. Esta hipótese de Feenstra $e t$ al. (2000) é satisfeita parcialmente no caso dos países da América Latina. Uma explicação para essa divergência é que em uma amostra mundial o comércio dos países industrializados tem um peso significativo e, portanto, o peso dos bens homogêneos associados a bens primários é menor.

\section{CONSIDERAÇÕES FINAIS}

Este trabalho comprova empiricamente certas teorias econômicas para a realidade da América Latina, mas a potencialidade da metodologia de Feenstra et al. (2000) vai além disso, pois permite analisar mudanças no comércio exterior da América Latina na década de 1980 e as características das relações comerciais da região com outros blocos de comércio.

Nessa perspectiva, as conclusões mais amplas que podem ser obtidas são as expostas a seguir. Primeiro, para o caso da América Latina, prova-se que para as exportações de bens diferenciados a organização industrial vigente é de concorrência monopolista com rendimentos crescentes, mas com livre entrada. Este resultado é conseqüência do fato de que a quantidade de produtos diferenciados dos países da OECD é maior que na América Latina e, neste caso, os países da América Latina são importadores de bens diferenciados. Por falta de espaço, não foi incluída uma simulação que identificava os países da América Latina onde a presença de rendimentos crescentes era mais intensa. Segundo, o resultado mostra que os países de maior dimensão do continente (Argentina, Brasil e México) têm maior intensidade de economias de escala. Isto prova que, com mercados de dimensão maior, há uma entrada desproporcional de empresas, a concorrência é mais forte e os preços são mais baixos. Esses países são, portanto, exportadores líquidos de bens diferenciados para outros países da região e para o resto do mundo.

Demonstra-se que, para o caso dos bens homogêneos da América Latina, os exportadores da região obedecem a um comportamento de dumping recíproco. Nesta situação, também se pode observar que, no caso do intercâmbio regional destes produtos, há no mercado interno rendimentos crescentes. Porém, pela pouca significação que tem o comércio regional de produtos básicos para os exportadores de América Latina, o comportamento dominante é o que se assinala no início do parágrafo. 
O trabalho permite conferir as mudanças no comércio internacional de 1985-1990, em relação ao período anterior. Levar em conta um qüinqüênio para avaliar mudanças estruturais pode ser considerado um período de tempo pequeno. Não obstante esta situação, observam-se mudanças no comércio exterior da América Latina no período da pesquisa. Nos anos 1985-1990, as elasticidades de exportações em relação ao produto do país exportador tiveram incremento em relação ao período anterior para os bens diferenciados com referências de preços. Isto está associado à importância das exportações de bens intermédios da região. Para os bens diferenciados com referência de preços, a elasticidade em relação ao produto do parceiro aumentou. Este último fenômeno significa que os países da região incrementam o comércio intra-industrial.

Em relação aos APC, pode-se afirmar que as empresas exportadoras de América Latina adquiriam economias de escala para os bens diferenciados, ou seja, existe uma relação positiva entre as exportações e os ACP.

Diante do exposto, cabe afirmar que essa relação não tem tendência definida no tempo, bem como pode-se defender que no período 1985-1990 as empresas exportadoras obtiveram maiores economias de escala e, portanto, adquiriram um maior poder de mercado no mercado interno, como conseqüência de sua inserção internacional. Este poder de mercado se traduz em maiores preços no mercado interno e perdas de bem-estar. Este, porém, é um tema para outra pesquisa.

\section{REFERÊNCIAS}

Anderson, J.; Winccop, E. Gravity with gravitas: a solution for border puzzle. National Bureau of Economic Research - NBER, Working Paper n. 8079, 2001.

Azevedo, A. F. Z. What has been the real effect of Mercosul on trade a gravity model aproch. Texto para Discussão. Porto Alegre: Universidade Federal de Rio Grande do Sul, 2001. Mimeografado.

. O efeito do Mercosul sobre o comércio: uma análise com o modelo gravitacional. Pesquisa e Planejamento Econômico, v. 34, n. 2, agosto de 2004.

Buitelar, R.; Martens, L. The challenge of industrial competitiveness. CEPAL Rewiew, 51, Santiago, 1996.

BID. New regionalism in Latin America. Disponível em: www.idb.org/workpapers, 2002.

Davis, D.; Weinstein, D. Does economic geography matter for international specialization? National Bureau of Economic Research -NBER, Working Paper n. 5706, September 1996.

Eichengreen, B.; Irwin, D. The role of the history in bilateral trade flows. In: Frankel, J. (ed.), Regionalization of the world economy. Chicago: University of Chicago Press, 1994, p. 33-57.

Feenstra, R.; Markusen, J.; Rose, A. Understanding the home market effect and the gravity equation: the role of differentiating goods. National Bureau of Economic Research -NBER, Work Paper n. 6804, November 1998.

. Using the gravity equation to differentiate among alternative theories of trade. Disponível em: http://faculty.haas.berkeley.edu/arose/FMRrev.PDF, September 2000.

Fitzgerald, E. V. K. El Nuevo régimen comercial, la conducta macroeconómica y al distribución del Ingreso en América Latina, En el Nuevo modelo económico en América Latina, su efecto en la distribución del ingreso y en la pobreza. In: Blumer-Thomas, Victor (org.) El Trimestre Económico, Lecturas, México 1997.

Helpman, E. Increasing returns, imperfect markets and trade theory. In: Jones, R. W.; Kenen, P. B. (eds.), Handbook of international economics, vol. I. Elsevier Science Publisher, 1984. 
Hidalgo, A B.; Vergolino, J. R. O nordeste no comércio inter-regional e internacional: um teste dos impactos por meio do modelo gravitacional. Economia Aplicada, v. 2, n. 4, p. 707-725, out./dez. 1998

Lora, E. Las reformas estructurales de América Latina? Qué se ha reformado y como medirlo. Banco Interamericano de Desarrollo, versión actualizada del documento 348, Washington DC EUA, Junio de 1997.

Krugman, P. Trade and gains from trade with imperfect competition. American Economic Review, 70, p. 950-959, 1980.

McCallum, J. National borders matter, Canada-US regional patterns. American Economic Review 85, p. 615-623, June 1995.

Nitsh, V.; Sturm, D. The trade liberalization effects of regional trade agreements. Berlim: Bakgesellschaft, June 2004.

Obstfeld, M.; Rogoff, K. The six major puzzles in international macroeconomics: is their a commom cause? National Bureau of Economic Research -NBER, Working Paper n. 7777, July 2000.

Piani, G.; Kume, H. Fluxos bilaterais de comércio e blocos regionais: uma aplicação do modelo gravitacional. Texto para Discussão n. 749, Rio de Janeiro: IPEA, julho de 2000.

Prasley, D.; Wei, S-J. Explainig the border effect: the role of the exchanche rate variability shipping cost and geography. National Bureau of Economic Research -NBER, Working Paper n. 7836, August 2000.

Poyhonen, P. A tentative model for the volume of trade between countries. Weltwitsschatliches Archiv, 90, p. 93-99, 1973.

Porto, P. S. Mercosul and regional development in Brazil: a gravity model approach. Estudos Econômicos, São Paulo, v. 32, n. 1, p. 125-153, jan./mar. 2002.

Porto, P. S.; Canuto, O. Mercosul gains from regional integration and exchanche rate regimes. Economia Aplicada, v. 6, n. 4, p. 658-679, out./dez. 2002.

. Uma avaliação dos impactos regionais do Mercosul usando dado de painel. Pesquisa e Planejamento Econômico, v. 4, n. 3, p. 466-489, 2004.

Rauch, E. J. Network versus markets in international trade. National Bureau of Economic Research -NBER, Working Paper n. 5617, June 1996.

Tinbergen, J. Shaping the world economy: suggestion for an international economy policy. New York: Twentieth Century Fund, 1962.

Wei, S-J. Intra-national versus International trade: How stubborn area nations in global integration. National Bureau of Economic Research -NBER, Working Paper n. 5531, April 1996. 


\section{APÊNDICE - PAÍSES CONSIDERADOS NA AMOSTRA}

\begin{tabular}{|c|c|c|}
\hline África do Sul & Emirados Árabes Unidos & Jamaica* \\
\hline Angola & Equador* & Japão \\
\hline Arábia Saudita & Espanha & Jordânia \\
\hline Argélia & Etiópia & Kuweit \\
\hline Argentina* & EUA & Laos \\
\hline Austrália & Fiji & Libéria \\
\hline Áustria & Filipinas & Madagascar \\
\hline Bahamas* & Finlândia & Malásia \\
\hline Bahrein & França & Malavi \\
\hline Bangladesh & Gabão & Mali \\
\hline Barbados* & Gâmbia & Malta \\
\hline Belize* & Gana & Marrocos \\
\hline Benim & Grécia & Mauritânia \\
\hline Bolívia* & Guatemala* & México* \\
\hline Brasil* & Guiana* & Miamar \\
\hline Bulgária & Guiné & Moçambique \\
\hline Burkina Passo & Guiné Bissau & Mongólia \\
\hline Burundi & Haiti* & Nepal \\
\hline Butão & Holanda & Nicarágua* \\
\hline Camarões & Honduras* & Niger \\
\hline Canadá & Hong-Kong & Nigéria \\
\hline Chade & Hungria & Noruega \\
\hline Checoslovakia & Iemen & Nova Zelândia \\
\hline Chile* & Ilhas Mauricio & Omã \\
\hline China & Índia & Pakistão \\
\hline Chipre & Indonésia & Panamá \\
\hline Cingapura & Irã & Papua Nova Guiné \\
\hline Colômbia* & Iraque & Paraguai* \\
\hline Comores & Irlanda & Peru* \\
\hline Congo & Is. Salomon & Polônia \\
\hline Costa Rica* & Islândia & Portugal \\
\hline Dinamarca & Israel & Qatar \\
\hline Djibuti & Itália & Quênia \\
\hline Egito & Iugolávia & República Centro Africana \\
\hline El Salvador* & Ivory Cost & República da Coréia \\
\hline
\end{tabular}


República Democrática Alemã România

República Dominicana*

República Federal Alemã

Reunion*

Ruanda

Senegal

Serra Leoa

Seychelles

Síria

Somália
Sri Lanka

St. Crist. e Nevis*

Sudão

Suécia

Suíça

Suriname

Tailândia

Taiwan

Tanzânia

Togo
Tunísia

Turquia

U.K. (Reino Unido)

U.R.S.S.

Uganda

Uruguai*

Venezuela*

Zaire

Zâmbia

Zimbábue

* Países da América Latina incluídos na amostra. 